\title{
A comprehensive modeling study of in-cylinder fluid flows in a high-swirl, light-duty optical diesel engine
}

\author{
Federico Perini ${ }^{\mathrm{a}, *}$, Paul C. Miles ${ }^{\mathrm{b}}$, Rolf D. Reitz ${ }^{\mathrm{a}}$ \\ ${ }^{a}$ Engine Research Center, University of Wisconsin-Madison, Madison, WI 53706 \\ ${ }^{b}$ Combustion Research Facility, Sandia National Laboratories, Livermore, CA 94550
}

\section{Abstract}

The effectiveness of computational fluid dynamics modeling as a tool for researching fuel-lean, low temperature engine combustion strategies relies on its capability to capture the local fluid flow properties that affect spray dynamics, mixture preparation and ignition kinetics. In this study, a comprehensive model of an optically accessible, single-cylinder light-duty diesel engine was developed for engine combustion research. The computational model includes the realistic combustion chamber and ducts geometries. Variable orientation throttles in the intake ducts were modeled to reproduce variable swirl generation. Full induction stroke calculations were run over a portfolio of intake swirl conditions, and validated against extensive measurements featuring global intake swirl ratios, in-cylinder particle image velocimetry (PIV)-measured velocity fields and swirl centers. The results showed good agreement with the experiments, and the model was used to understand the effects of different swirl generation strategies on the in-cylinder flow field. The implications of using simplified sector mesh geometries on the predic-

\footnotetext{
${ }^{*}$ Corresponding author. Phone: +1-608-658-0985

Email address: perini@wisc.edu (Federico Perini)
} 
tiveness of in-cylinder flow and turbulence quantities are described.

Keywords: engine CFD, swirl modeling, light-duty diesel engine, PIV, swirl center, RANS, KIVA

\section{Introduction}

Energy efficiency and environmental sustainability concerns are driving internal combustion engine research towards looking for more effective combustion strategies that can maintain extremely low emissions levels in-cylinder, while achieving very high indicated efficiencies [1]. Homogeneous-charge, partially-premixed and reactivity-controlled compression ignition (HCCI, PPCI, RCCI) combustion strategies rely on forming locally ignitable mixtures at typically highly dilute and low temperature limits [2]. All of these strategies present a number of challenges from the modelling point of view. In partially-premixed compression ignition (PPCI) combustion, in particular, fuel is directly injected into the combustion chamber earlier than in conventional diesel combustion modes, to allow for premixed mixture preparation prior to ignition. Dilute, low-temperature charge conditions and high swirl ratios enable the feasibility of this combustion mode, allowing time for some degree of premixing to be achieved for all the fuel; however, the heterogeneous presence of locally fuel-lean and locally fuel-rich mixtures at the ignition can lead to significant engine-out carbon monoxide (CO) and unburned hydrocarbons (UHC) emissions arising from bulk overly-lean regions that do not completely ignite [3].

High-speed, direct-injection Diesel engines (HSDI) are particularly suit- 
able for applying low-load, partially premixed combustion strategies, due to their swirl-tailored-intake-duct designs that allow high swirl ratios to be achieved within the combustion chamber, fostering fuel-air mixing before ignition of the richest regions occurs $[4,5]$. The light-duty optical diesel engine facility at the Sandia National Laboratories (SNL) has provided significant insight into the mechanisms that rule the sources of UHC and CO emissions arising from low-load PPC combustion [3-13]. In the studies, a Planar Laser Induced Fluorescence (PLIF) based experimental technique was developed to analyze local mixture formation by evaluating the local distribution of equivalence ratios throughout most of the combustion chamber volume. Experiments were performed at different horizontal planes that spanned the squish region, the piston rim region where jet impingement occurs, and the deep in-bowl region which is affected by bowl shape design. A comprehensive review of these local equivalence ratio measurements for PPC engine operation can be found in [14]. Detailed studies on the fluid flow properties of this engine facility were carried out by Opat [15] and Petersen [16]. These comprehensive experimental studies provide a unique quantitative validation opportunity for engine computational fluid dynamics (CFD) models.

Widely adopted sector mesh engine simulations have not been able to capture local mixture preparation and jet-to-jet differences that are responsible for most of UHC and CO emissions [5, 17], even when excellently reproducing the overall in-cylinder ignition behavior. For this reason, the focus of the present study was a thorough description of the engine fluid flow properties, using a comprehensive computational model of the experimental engine facility. Validations are performed against flow-bench swirl and in-cylinder PIV 
measurements. The importance of correct fluid flow modeling for high-speed, direct-injected diesel engines, and the usefulness of PIV measurements as a tool for understanding the fluid flow structures and to support the modeling, are well established [18-24]. The model was used to study the implications of the interactions between the flow field and temperature stratification on the formation of pollutants in globally lean, low-temperature combustion strategies.

The paper is structured as follows. First, the computational model is described with a focus on the modeling of the variable-swirl generation throttles. Then the fluid flow predictions at a number of swirl conditions against measurements of swirl ratios, local velocities, and swirl center positions, are validated for full induction stroke calculations in motored engine operation. Finally, the validated model is used to study the effects of different throttling strategies on the in-cylinder fluid flow structure, and compared with sector mesh simulations. The results show the good accuracy of the Reynolds-averaged Navier Stokes (RANS) approach in capturing ensemble-averaged flow field properties, the significant differences in the average velocity field caused by different throttling strategies, and the substantial lack of resolution of simplified sector mesh modeling at capturing local average and turbulent quantities.

\section{Engine model development}

The engine is derived from a modified 1.9L General Motors (GM) production engine. The optical piston assembly retains the full geometric properties of the production piston, with slight differences in the top land ring crevice 
volume, fitted for experimental imagery [7]. As a basis for the fluid flow calculations, an unstructured version of the KIVA family of codes was used [2527]. The code solves the RANS ensemble-averaged Navier-Stokes equations on complex engine geometries using an arbitrary Lagrangian-Eulerian (ALE) scheme. Fluid flow turbulence is accounted for by means of the ReNormalization Group (RNG) closure for the two-equation k- $\epsilon$ model [28]. In order to match the non-negligible compressibility of the optical piston assembly, a previously validated static compressibility model for the connecting rod was used [5]. The code also features additional models for efficient combustion chemistry calculations, including a sparse analytical Jacobian chemistry code for chemical kinetics (SpeedCHEM) [29, 30] and a high-dimensional cell clustering algorithm [31, 32].

The computational grid of the single cylinder engine features 559867 cells and 585189 vertices, and was developed based on the detailed geometry files of the combustion chamber, cylinder head, intake and exhaust ducts and runners, as shown in Figure 1. The intake section was modeled up to the intake plenum, including the merging cross section ducts at the intake plenum flange. The chamfered piston geometry, including the bowl shape, valve cutouts and top land ring crevice was obtained from the optical piston assembly. The unstructured grid capability kept the number of cells in the discretized geometry as low as possible, while resolving the fluid flow in the near-valve regions and at the walls. Circular geometric features, including the piston bowl, cylinder liner, as well as the valves and their seats, were modeled making use of o-grid structures that allow body-fitted meshes with high-quality 
and optimal aspect-ratio cells that avoid non-convex or degenerate cells at the walls that could cause solution convergence problems. Finally, in order to achieve a numerically converged prediction of the intake mass flux through the valves, the code was modified to allow an arbitrary number of cell layers at the valve opening, to describe the valve skirt, so that the valve profiles could be faithfully modeled. It was found that using 13 cell layers at the maximum valve lift provided converged intake mass flow predictions.

The experimental setup from low-load, slightly boosted PPC operating conditions was used to set the initialization and boundary conditions for the induction stroke simulations, as represented in Figure 2 and reported in Table 1. As Figure 2 shows, some assumptions were needed for the temperature field initialisation. As for the pressure and velocity fields, different initial simulation crank angles before the exhaust valve closing (EVC) were tested and it was seen that all the simulations quickly converged to the same in-cylinder conditions after the end of the valve overlap period.

\section{Variable intake swirl device modeling}

In the experimental engine facility different intake swirl ratios are achieved by means of throttling devices placed in the intake ports [15, 33]. A metal plate, similar to the one represented in Figure 3, is placed between the cylinder head and the intake runners. The intake air flows through two throttlerestricted ducts whose cross-sectional area is constant, and has the same shape as at the junction between the head and the intake runners. Both throttles are fixed, by means of a system of pins placed at the top of the throttling device, at different angles that vary from 0 (throttle fully closed) 

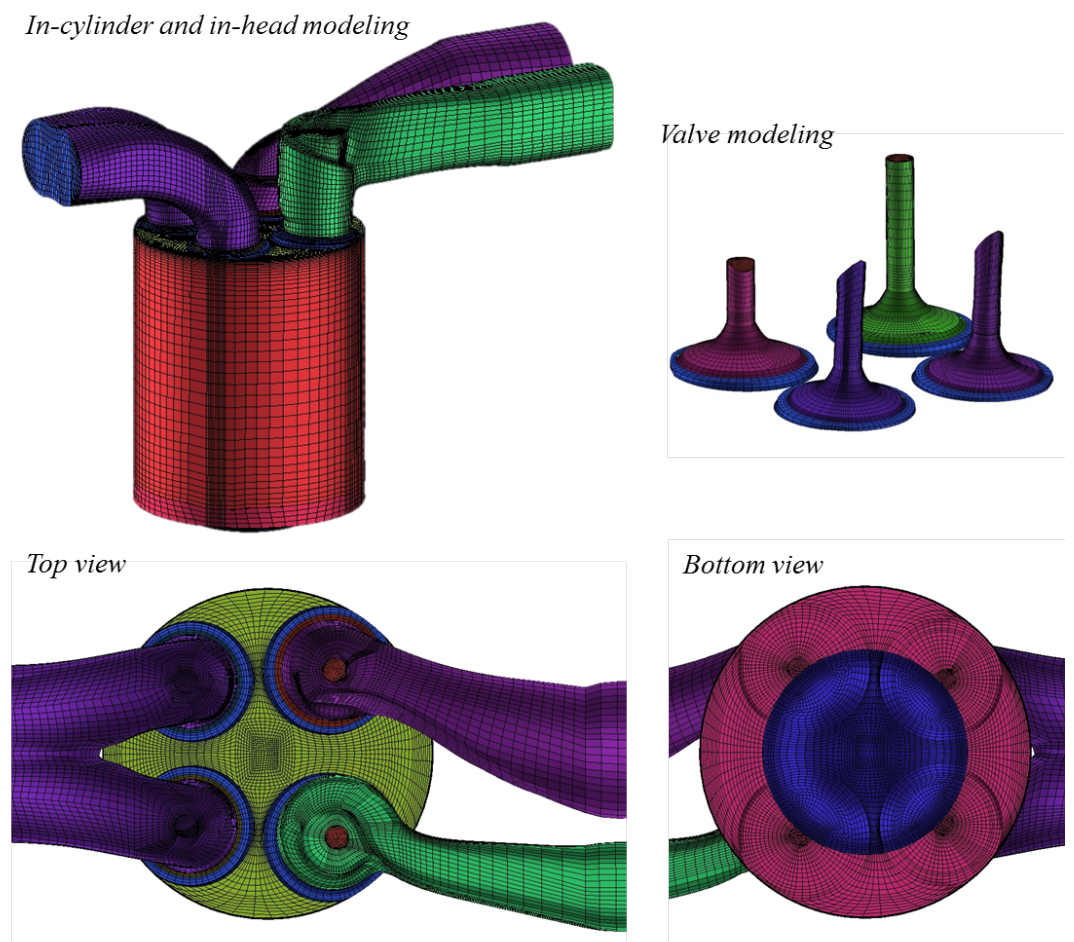

Figure 1: Meshing details for the combustion chamber and head regions. 


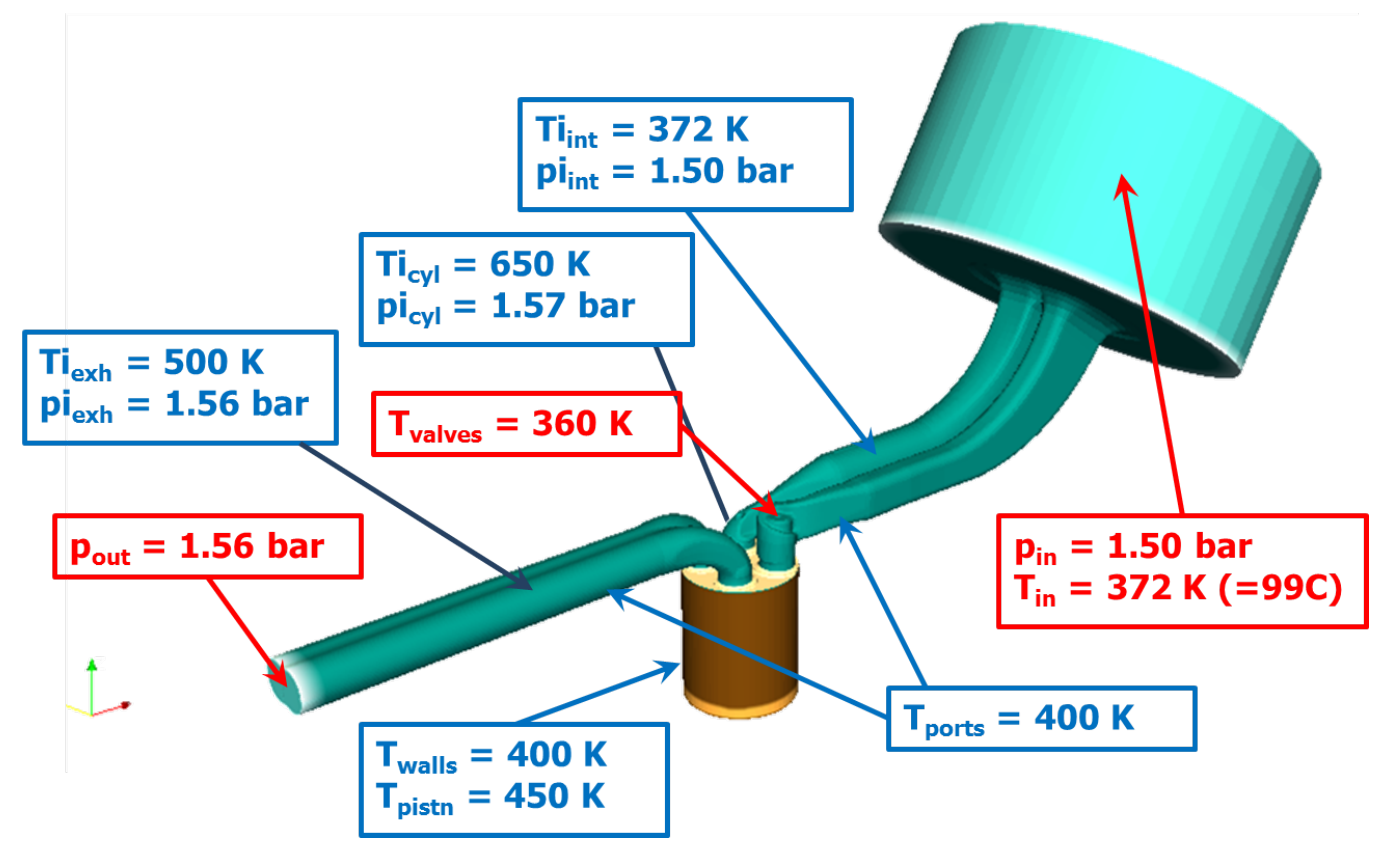

Figure 2: Computational model initialisation for induction stroke simulations. Red items represents experiment-based settings; blue items represent assumed values. 


\begin{tabular}{lc} 
Engine specifications & \\
\hline Bore x stroke $[\mathrm{mm}]$ & $82.0 \times 90.4$ \\
Displacement $\left[\mathrm{cm}^{3}\right]$ & 477.2 \\
Nominal compression ratio & $16.4: 1$ \\
Squish height at top dead center (TDC) $[\mathrm{mm}]$ & 0.88 \\
\hline Operating conditions & 1500 \\
\hline Engine speed $[\mathrm{rev} / \mathrm{min}]$ & $10 \% \mathrm{O}_{2}$ \\
& $81 \% \mathrm{~N}_{2}$ \\
Intake charge composition $[\mathrm{mole} \mathrm{fr}]$. & $9 \% \mathrm{O}_{2}$ \\
& 1.5 \\
Intake pressure $[\mathrm{bar}]$ & 1.56 \\
Exhaust pressure $[\mathrm{bar}]$ & 372 \\
Intake temperature $[\mathrm{K}]$ &
\end{tabular}

Table 1: Engine specifications and operating conditions for the validation cases. 
to 90 degrees (throttle fully open). In the experiments, 20 equally-spaced pins, numbered from 0 to 19 , were used that subdivide the total angle span. Different throttling strategies are used to generate higher or lower swirl ratios than the original, non throttled engine configuration, that has a nominal swirl ratio of $R_{s}=2.2$. As seen in Figure 4, the flow within the helical port has higher velocities than that within the tangential port, and when entering the combustion chamber it fosters intense local vortical structures. On the other hand, flow entering the combustion chamber from the tangential port adds a significant amount of momentum with no particular vortical structure, but is diverted by the cylinder wall to generate a swirling structure on the scale of the cylinder bore. The helical port is typically throttled in order to achieve higher swirl ratios. In this case, the pressure drop induced by the throttle reduces the mass flow through the helical port, and a greater percentage of the inducted mass flows through the tangential port where it contributes efficiently to the generation of large-scale swirl structures. In order to achieve lower swirl ratios, the tangential port is throttled. The throttling reduces the total momentum re-directed into large-scale swirl structures, leaving most of the swirl generation to the helical port flow. As the flow entering from the helical port is more localized, with a swirl center that is offset from the cylinder axis, it does not contribute as effectively to the large-scale swirl as the flow through the tangential port. Moreover, there is significant interaction between the flows from the two ports, which can result in a non-monotonic variation in swirl generation as the various ports are throttled. Generally, the variation in swirl is considerably more complex as the tangential port is throttled. 

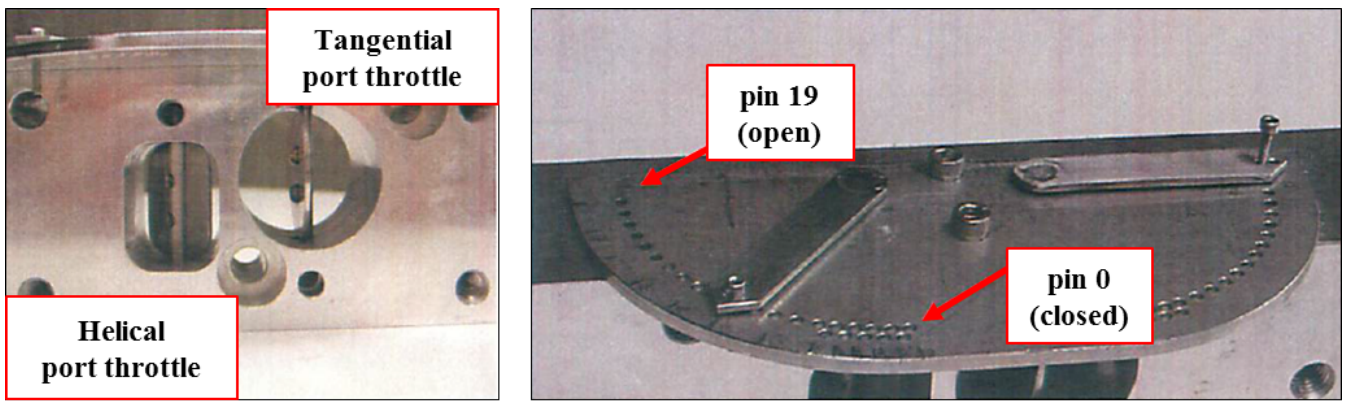

Figure 3: Intake port throttling devices (photograph). Left: detail of helical (rectangular shape) and tangential (round shape) throttles and ducts. Right: detail of throttle orientation system

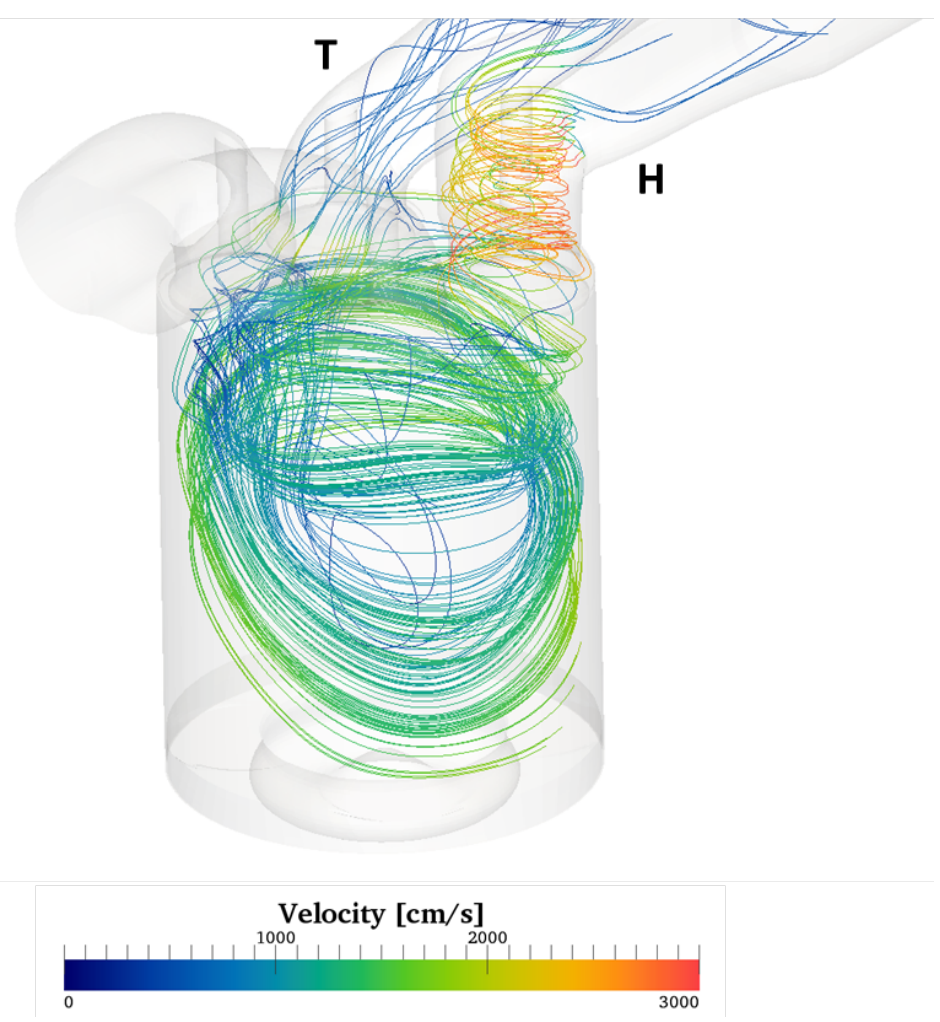

Figure 4: Predicted velocity streamlines at bottom dead center (BDC) during the intake stroke. Non throttled engine configuration. Streamline seed centered $1 \mathrm{~cm}$ below firedeck, radially displaced $2.5 \mathrm{~cm}$ towards the intake ducts. 


\subsection{Modelling of the throttling devices}

A code was developed for generating throttle valves with arbitrary orientation in the mesh, as follows:

1. The cell layer to be deactivated in the grid topology was identified;

2. For nearly closed throttles, two near-wall vertical cell side columns were kept as fluid cells to prevent the throttle from fully closing;

3. The throttle plate cell flags were set to 'inactive', and all of their face flags were set to 'solid wall';

4. The thickness of the cell layer was modified to the throttle valve thickness;

5. Throttle nodes were rotated around the throttle axis, and the surrounding duct nodes accordioned at progressively smaller angles, so as to both avoid non-convex cells, and to keep a good cell aspect ratio in the region surrounding the throttle.

Figure 5 reports example results of the throttle generation procedure. At the top both throttles are rotated to pin 15, corresponding to an opening angle of $71.05^{\circ}$, and a stream-wise layer of cells is used for the generation. At the bottom, they are rotated to pin $3\left(15.00^{\circ}\right)$, and a cross-sectional layer is used for the generation. As the figure shows, the modeled throttle geometry is simplified. No stem is modeled, whose width may have an impact on the intake flow when the throttle is almost completely open. Furthermore, the throttle surface is assumed to be a rectangular-shaped plate, and its area deviates from the exact one when the throttle is in near-closed position, as two cell layers need to be left for the fluid flow modelling. Note also that, in 

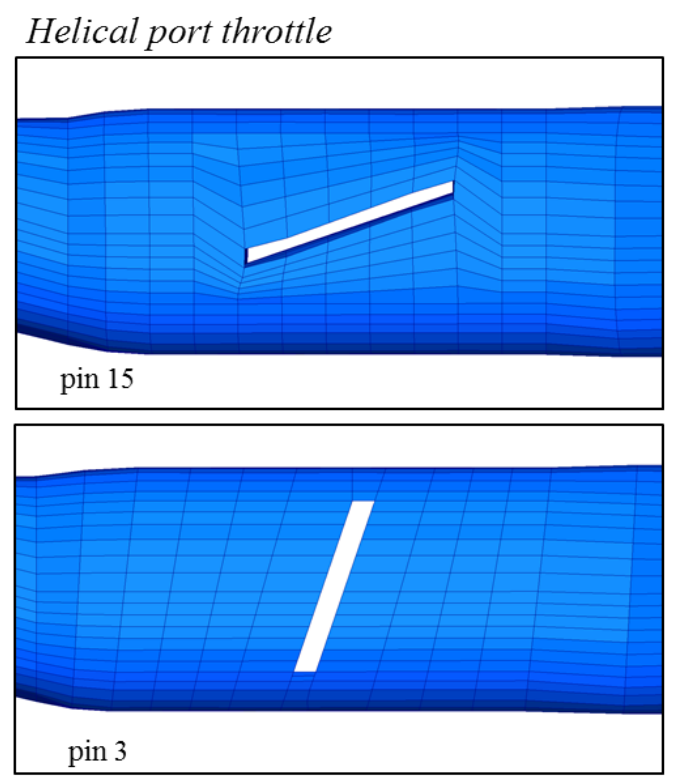

Tangential port throttle
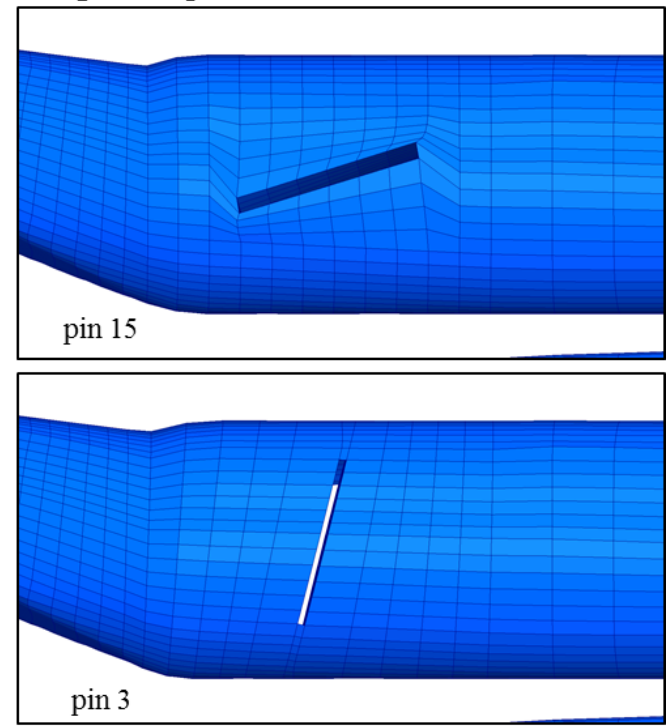

Figure 5: Computational modelling of the intake port throttling valves: (left) helical port, (right) tangential port throttle.

these latest conditions, having only one layer of fluid cells between the two walls is consistent with velocity wall boundary layer treatment in the code.

\section{Results}

In order to reproduce in-cylinder intake fluid flow conditions, the simulations of the intake stroke were run, using the initial and boundary value settings reported in Figure 2, starting from crank angle $C A=340^{\circ}$ after top dead center (ATDC) (approximately 36 degrees before exhaust valve closing, and 5 degrees before the intake valve opening). This initialization was chosen after a sensitivity analysis study where it was seen that initial simulation times up to $C A=300^{\circ} A T D C$ did not change the predicted flow field structure and swirl ratio values noticeably. 


\subsection{Intake swirl ratio}

The full engine geometry with intake throttle valve generation methodology was validated against flow-bench swirl ratio measurements carried out with the same cylinder head [15]. Two sets of experimental swirl ratio measurements were available. One, featuring throttling of the helical port, with the tangential port in the fully open configuration; and one, where the tangential port was throttled, with the tangential port set at three different positions: fully open (pin $=19)$, and partially open $(\operatorname{pin}=15$ and $\operatorname{pin}=11)$. In order to evaluate the swirl ratio from the simulations, a common momentumbased definition was applied to the velocity field in the cylinder region as [25]:

$$
R_{s}=\frac{60}{2 \pi n} \frac{\sum_{i} m_{i}\left[\left(x_{i}-x_{C}\right) v_{i}-\left(y_{i}-y_{C}\right) u_{i}\right]}{\sum_{i} m_{i}\left[\left(x_{i}-x_{C}\right)^{2}-\left(y_{i}-y_{C}\right)^{2}\right]},
$$

where $C=\left(x_{C}, y_{C}, z_{C}\right)$ represents the center of mass of the whole combustion chamber fluid region, $i$ is the loop index on all cylinder fluid nodes, where velocities are stored in the staggered grid approach, $m_{i}$ is the mass of the momentum cell around the $i$-th node, $\left(u_{i}, v_{i}, w_{i}\right)$ the instantaneous velocity components at node $i$, and $n=1500 \mathrm{rev} / \mathrm{min}$ the current engine rotational speed. Figure 6 reports the average cylinder swirl ratio behavior during the induction and compression strokes, when throttling the helical port. In this transient flow condition, and for all the port configurations, the swirl ratio had a maximum around $-240^{\circ} A T D C$, approximately 30 degrees after the piston reached its maximum velocity point during the intake stroke.

These results highlight how transient flow conditions cannot be directly compared to steady state measurements carried out on a swirl meter bench, where no piston is present and the pressure drop across the valves is fixed. 
Although the transient flow can be approximated as a weighted sum of steady flow bench results at multiple valve lifts, it should be noted that even with the accurate impulse-based swirl meter of [15], the results can be affected by a $10 \%$ error bias [34]. From the present results, it appears that the closest approximation to the weighted swirl bench result occurs at $C A=$ $-270^{\circ}$, when the piston is at its maximum velocity and the intake valves are approaching the maximum lift near $C A=465^{\circ}$. The peak swirl ratio was predicted to occur at approximately $C A=-240^{\circ}$, indicating that the generation of swirl is dominated by the flows entering the cylinder at high valve lifts - in agreement with measured flow bench data. After $C A=-240^{\circ}$, and up to about $C A=-190^{\circ}$, a steeper descent of the swirl ratio is seen as swirl decays and more mass enters the cylinder under less favorable swirl generating conditions. In this study, the maximum predicted swirl ratio during the intake was used as a reference for the comparison with the flowbench swirl data. The predicted in-cylinder local tangential velocity profiles were also compared with PIV measurements available for the same engine [16].

In Figure 7 the peak predicted intake swirl ratios when throttling the helical port were compared to the experiments in [15]. The experiments show deviations of up to $20 \%$, especially for the highest swirl configurations, where the helical port is almost completely closed. The simulations are seen to match the swirl trends with the different throttle orientations extremely well, and also the absolute predicted maximum swirl ratio values are very close to the experimental ones. For the 'fully open' throttle configuration with nominal $R_{s}=2.2$, where interference of the throttle model with the intake flow is 


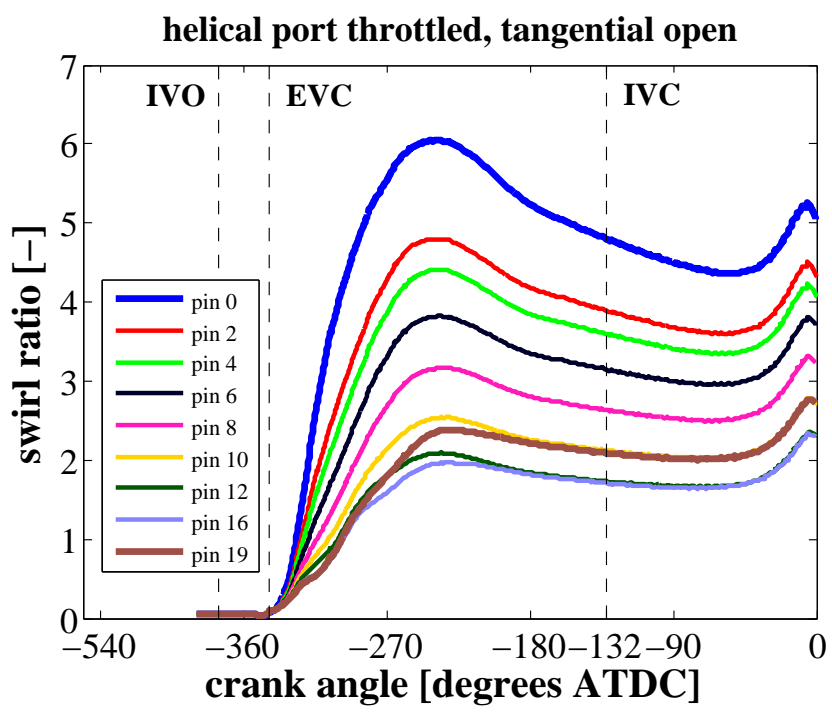

Figure 6: Predicted in-cylinder swirl ratios during the intake stroke. Tangential port open (pin $=19)$, helical port throttled.

minimal, the difference between predicted and measured swirl is of about $1.59 \%$.

Throughout all the tested throttle orientations two major critical regions for the simplified throttle model could be seen. First, a step in the predicted swirl was seen when moving from the fully closed throttle ( $\mathrm{pin}=0$, no intake flow through the helical port) to an almost closed configuration (pin $=2 \div$ 5). In this region, the modeled cross-sectional area closed by the throttle valve has the major deviations from the exact value due to the need to leave one layer of cells at the wall. However, two of the three sets of repeated experimental measurements show similar signs of a step in the swirl ratio when approaching the fully closed helical port configuration. As the velocity streamlines and contours suggest in Figure 8 for the closed $($ pin=0) and almost closed (pin=1) helical port configurations, closure of the helical port 


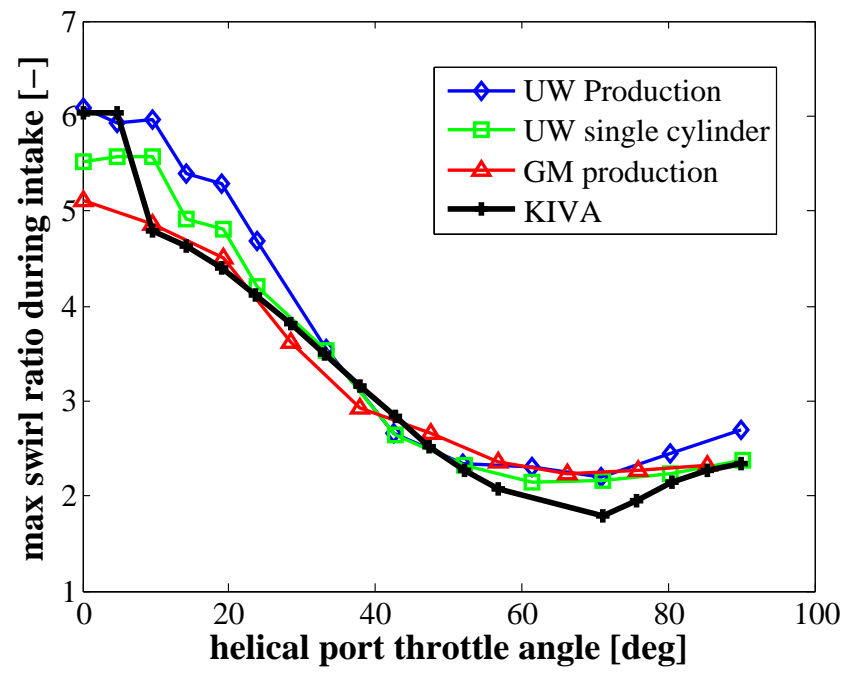

Figure 7: Comparison between measured (colors) and predicted (black) swirl ratio values at different helical port throttle orientations, and tangential port fully open. Experiments feature three different engine heads with the same nominal geometry.

results in a corresponding change in the in-cylinder flow structure. At this condition, the in-cylinder vortex structure is much more similar to a rigid vortex configuration than when some weak flow through the helical port is present too. In this case, the inner part of the vortex structure, close to the cylinder axis, shows significant tilting throughout the cylinder height.

Figure 9 reports the tangential port throttling validation at three different fixed orientations of the helical port throttle. Again, the model shows similar behavior to the experiments. When the helical port is in its fully open configuration (red line in the plot, or helical throttle fixed to pin 19), the helical throttle plate is placed streamwise, not significantly decelerating the flow. Thus, significantly larger velocities enter the combustion chamber from the helical port than from the tangential port in these cases (as also confirmed 


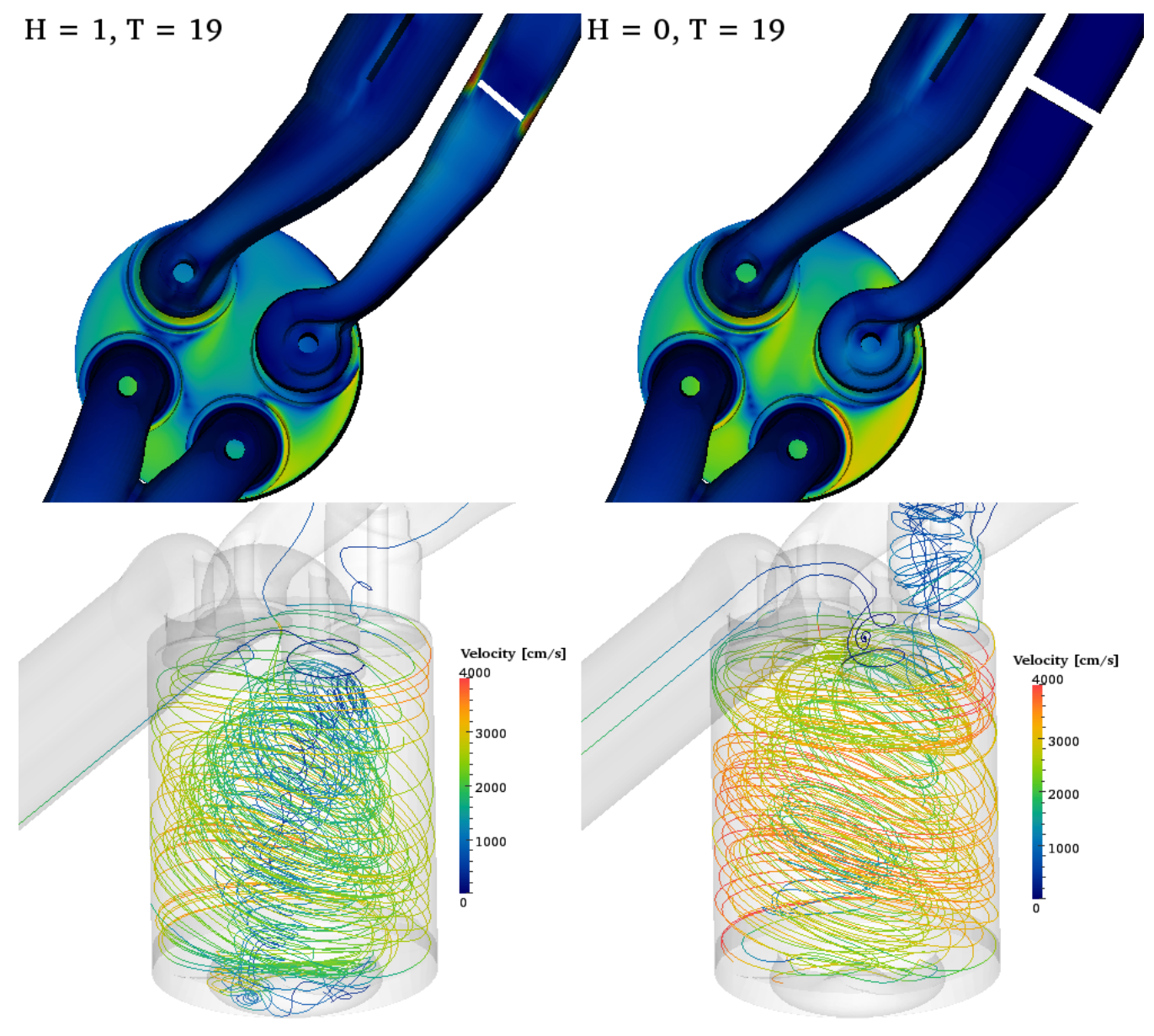

Figure 8: Comparison of predicted fluid flow structures at BDC during the intake stroke, tangential port fully open, helical port pin 1 (left) or 0, closed port (right). 
later, in Figure 19, case $R s=2.2$ ). In these simulations, the average relative error in the predicted swirl ratio with the measured steady state bench values was almost constant, and averaged about $5.59 \%$ for all valve orientation angles. The overestimation of flow deceleration which had been experienced for the partialized helical throttle was seen in the tangential port study too (green line, or helical pin $=15$; blue line, or pin $=11)$, resulting in overall performance being not as good as for the tangential port sweep with fullyopen helical port.

The simulations of Figure 9 also confirmed the different roles played by tangential port throttling in swirl generation. When throttling the tangential port, the overall swirl ratio decreases almost monotonically, confirming that the tangential port provides most of the large-scale swirl momentum. This trend is only interrupted when the tangential port throttle approaches very small opening angles, and the helical port is fully open. As in these cases most of the intake mass flows through the open helical port, if the tangential port allows for almost no flow to enter the cylinder, the spin created by the helical port shape is enough to keep the overall swirl ratio at values greater than $R_{s}=2.0$. This also confirms the effectiveness of the helical port shape as a swirl enhancer.

\subsection{In-cylinder tangential velocity profiles}

In order to establish a correlation between the predicted intake swirl ratios and the effective in-cylinder swirl velocities, a set of PIV measurements carried out during motored engine operation with the same experimental setup as that modeled was used [16]. In the experiments, the engine was op- 


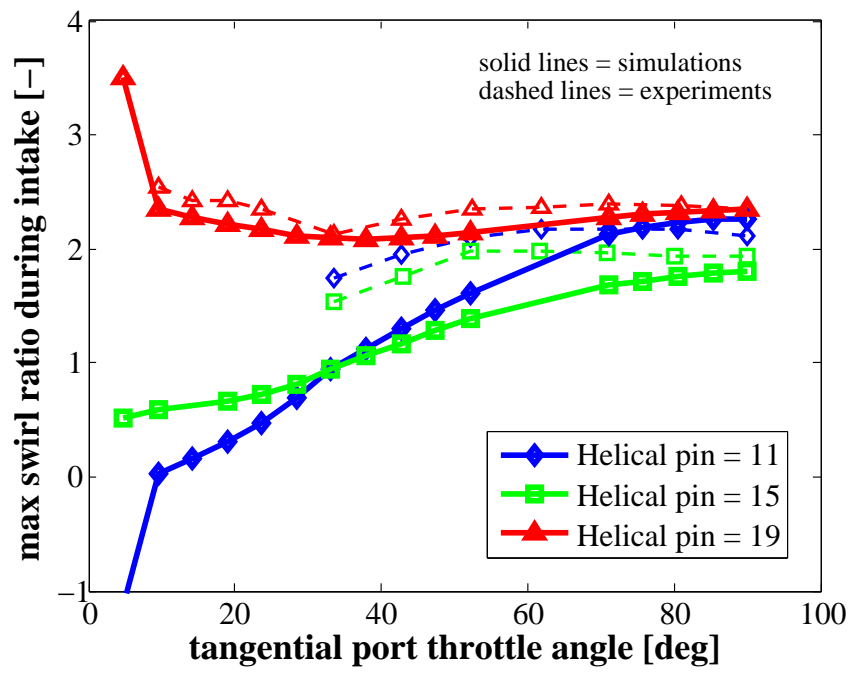

Figure 9: Comparison of measured (dashed lines) and predicted (solid lines) swirl ratios at different tangential port throttle orientations.

erated in motoring conditions with the same throttling strategies. Ensemble averaged velocity components were measured at fixed horizontal planes in the squish region during the compression stroke. Three different swirl ratios, nominally $R_{s}=2.2,3.5,4.5$, were tested whose valve orientation details are reported in Table 2 .

In sector mesh simulations, a tangential velocity profile is typically set within the combustion chamber at intake valve closure (IVC) with Bessel function behavior. In a previous study [5], the information provided by the experiments not only in terms of swirl ratio values, but also about the optimal Bessel function shape coefficient $(\alpha=2.20)$ for this engine were used to initialize sector mesh simulations. However, the results showed that the simulations significantly deviated from the measured velocity profiles as the 


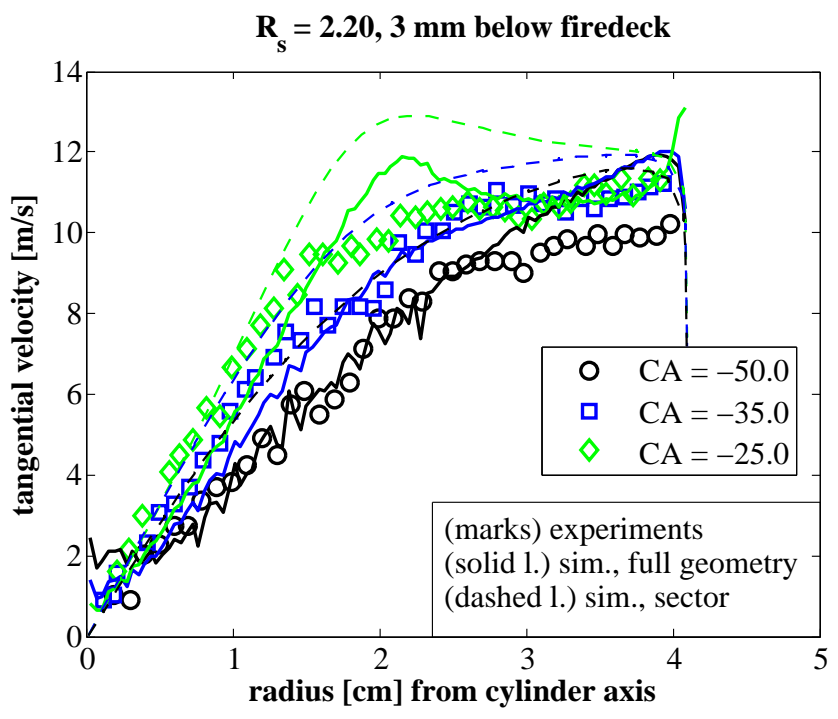

Figure 10: Azimuthally-averaged tangential velocity profiles, nominal swirl ratio $R_{s}=$ 2.20 , on a plane $3 \mathrm{~mm}$ below the firedeck, during the compression stroke. (marks) Experiments from [16], (solid lines) simulations with full geometry, (dashed lines) simulation with sector mesh and Bessel fit $(\alpha=2.2)$ velocity profile initialization.

piston approached TDC. Since injection occurs during the last part of the compression stroke, and the formation of lean air-fuel mixture regions that leads to significant amounts of $\mathrm{CO}$ and $\mathrm{UHC}$ is strongly influenced by the local flow field, this discrepancy is important.

The predicted tangential velocity profiles with the present full engine simulations are reported in Figures 10 and 11 for the throttle conditions of Table 2 (a shift of few pin positions towards smaller numbers and angles was applied to compensate for the smaller area of the simplified throttle). Data were also compared with results from the same cases, simulated using a sector mesh. The tangential velocity profiles were reconstructed by identifying the cell 


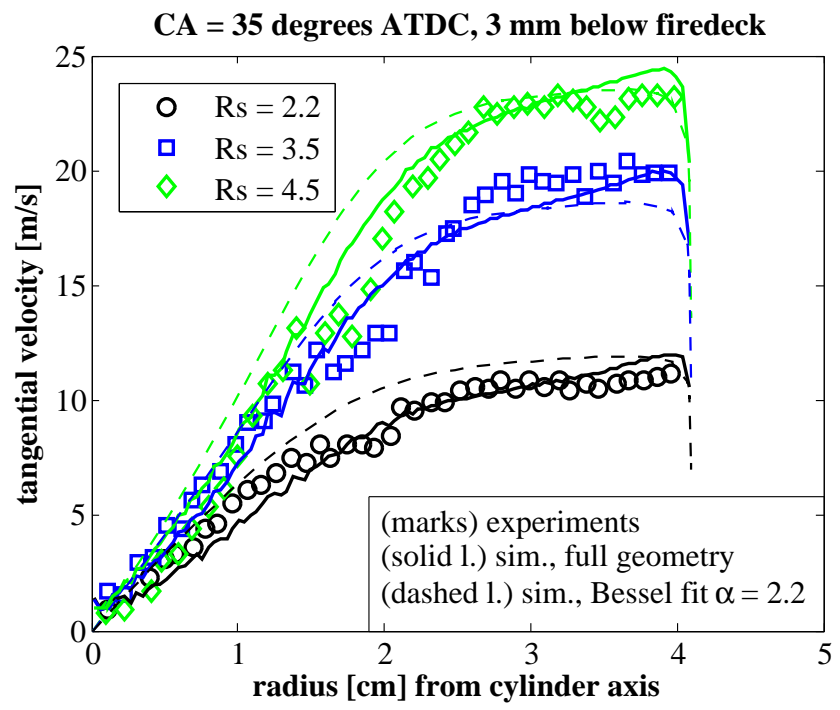

Figure 11: Azimuthally-averaged tangential velocity profiles, at $\mathrm{CA}=35$ degrees bTDC, on a plane $3 \mathrm{~mm}$ below the firedeck, at different nominal swirl ratio configurations. (marks) Experiments from [16], (solid lines) simulations with full geometry, (dashed lines) simulation with sector mesh and Bessel fit $(\alpha=2.2)$ velocity profile initialization. 
edges intersecting the measurement plane, and linearly interpolating their nodal velocity values to the horizontal plane. Then, the tangential velocities were calculated at the vertices, and binned into 100 uniformly spaced radial bins. The predicted velocity profiles at the nominal swirl ratio $R_{s}=2.2$ (wide open throttles), at a horizontal plane $3 \mathrm{~mm}$ below the fire-deck, at crank angles of 50,35, 25 degrees before top dead center (BTDC) during the compression stroke, are compared with the PIV measurements in Figure 10. The predicted profiles match well the experimental measurements at the three crank angles. The most significant deviation is seen where the piston is closest to top dead center, where a peak in the tangential velocity is predicted in the 2.0 to $2.5 \mathrm{~cm}$ radius interval. As the piston bowl rim radius is at $2.3 \mathrm{~cm}$ from the cylinder axis, this region was observed to be particularly challenging for the PIV measurements due to optical distortion caused by the curved bowl surfaces below the bowl rim region [16].

When the same cases were simulated using a sector mesh, the predicted tangential velocity profiles showed a noticeably different behavior. In the sector simulations no geometry details are present in the squish region such as the valve cut-outs. The comparison with the full geometry results shows that the lack of elements that oppose the swirling motion in this region leads to an overall overestimation of the tangential velocity profiles (Figure 10), and an overall higher velocity peak at the bowl rim. The absence of effects from geometric details is also evident when looking at different swirl ratio values. Comparing the full geometry simulations with the sector simulations in Figure 11, the sector predicted tangential velocities still follow Bessel-like 


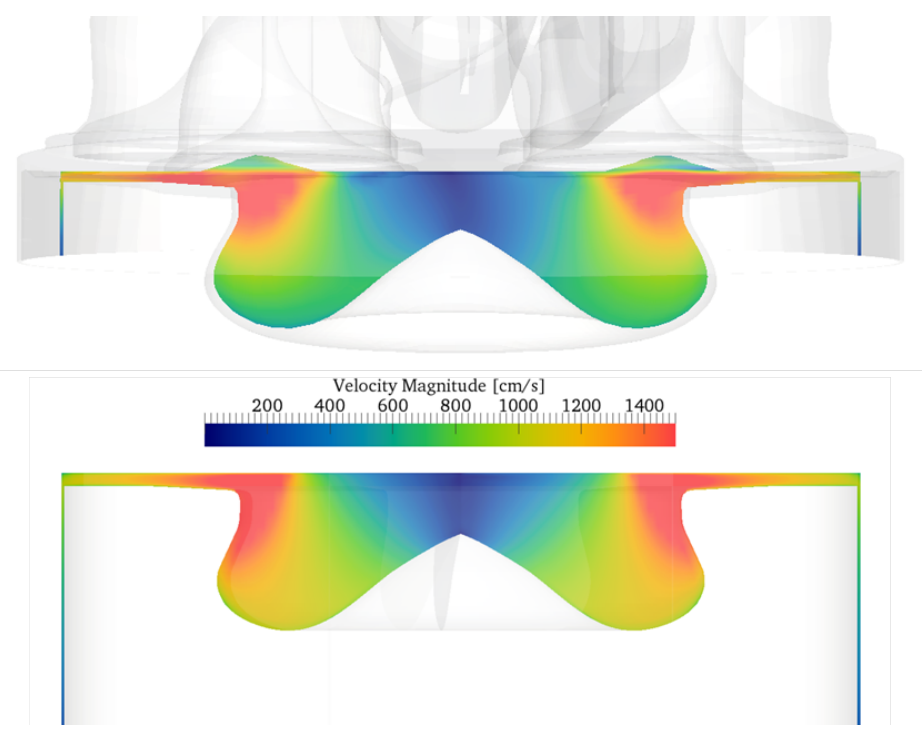

Figure 12: Comparison between full engine geometry (top) and sector mesh (bottom) predictions of in-cylinder velocity magnitudes at TDC, on a vertical cross-sectional plane bisecting the combustion chamber.

behavior at 35 degrees before TDC, while the full engine geometry simulation captures both the actual absolute velocity values, and the change in velocity trend that occurs at radii greater than about $2 \mathrm{~cm}$, yet due to bowl rim effects.

The comparison between sector mesh initialization and the induction stroke generated swirl from the full geometry simulation, shows that the vortical structure has differences that go beyond the averaged distribution of tangential velocity profiles. Looking at Figure 12, significant differences can be noted in the velocity field within the piston bowl at TDC when comparing the two different simulation approaches. While the full geometry simulation shows a region of high velocity magnitude near the piston bowl rim that extends inwards to the valve seat edge, the sector mesh simulation predicts 
higher velocity components until deep within the piston bowl. This effect was found to be primarily due to the flow field initialisation. When the sector mesh simulation is started, the flow field is set as a function of radius assuming that the swirling flow rotates within a perfectly cylindrical combustion chamber, and thus the velocity profile in the piston bowl has the same values as a function of radius as in the squish region of the combustion chamber. The full geometry simulations however show that this assumption is inappropriate, as the swirl momentum penetrates only marginally within the bowl. This is expected to have consequences on predictions of fuel spray penetration which is influenced by the in-cylinder flows.

The present comparisons with sector mesh predictions show errors in capturing local flow field properties due to the simplifications introduced by neglecting geometric details and inaccurate fluid flow initialization at the intake valve closure.

\begin{tabular}{ccccccc}
\hline \multicolumn{3}{c}{ Swirl ratio } & \multicolumn{3}{c}{ Experimental pin } & \multicolumn{2}{c}{ Modeled pin } \\
nominal & max. & IVC & T & $\mathrm{H}$ & $\mathrm{T}$ & $\mathrm{H}$ \\
\hline$R_{s}=1.5$ & 1.683 & 1.393 & 7 & 15 & 15 & 15 \\
$R_{s}=2.2$ & 2.389 & 2.091 & 19 & 19 & 19 & 19 \\
$R_{s}=3.5$ & 4.799 & 3.895 & 19 & 7 & 19 & 3 \\
$R_{s}=4.5$ & 6.039 & 4.804 & 19 & 5 & 19 & 1 \\
\hline
\end{tabular}

Table 2: Predicted swirl ratio values at the four reference operating conditions of [5].

\subsection{Swirl center tilt and precession}

As a result of the non-symmetric intake port design, the swirling flow has a non-axisymmetric structure. This has been thought to lead to differences 


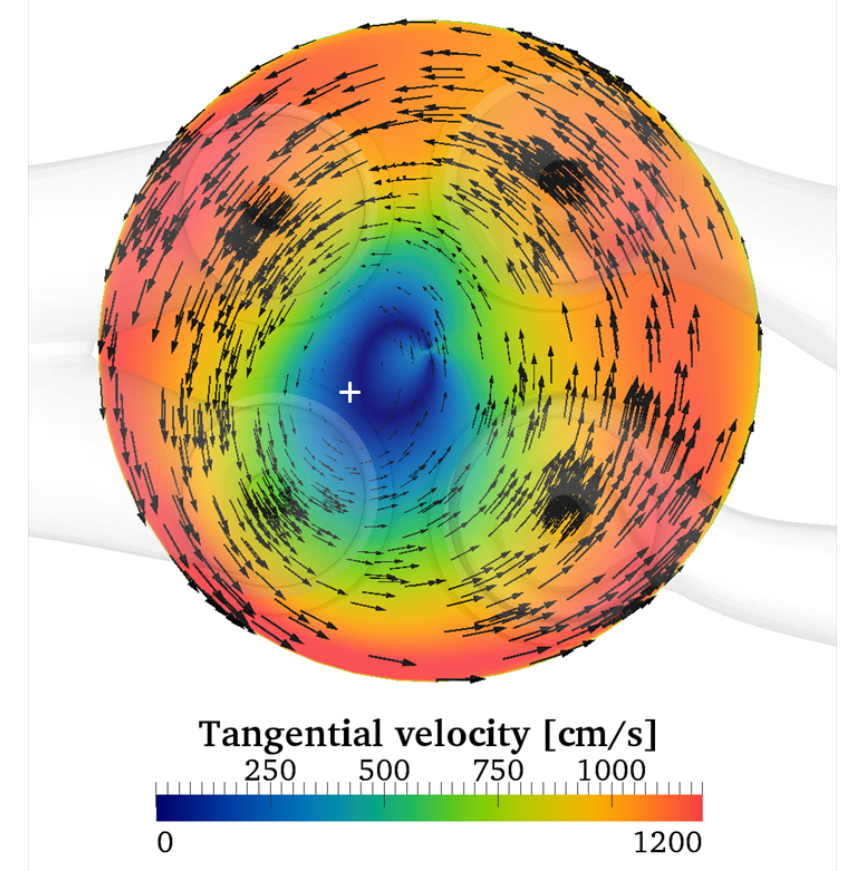

Figure 13: Predicted tangential velocity field at the measurement plane, $3 \mathrm{~mm}$ below firedeck, $R_{s}=2.2,50^{\circ}$ bTDC. ' + ' mark indicates calculated swirl center.

among the spray jets [22]. Indeed, the swirl center deviates from the cylinder axis, as shown in Figure 13 for one of the flow field validation cases. The experiments showed that, regardless of the intake throttling strategy, the swirl center exhibited two distinct behaviors [16]: 1) a counter-clockwise precession during the compression stroke, induced by the strong, coherent momentum entering the combustion chamber from the tangential port; 2) a vertical tilt behavior that shifts the swirl center towards the intake ports. In the experiments, the swirl center position was measured within the horizontal planes of the PIV measurements.

In order to identify the center of the three dimensional vortical fluid flow 
structures in the simulations, a similar procedure to the one adopted for the tangential velocity profile estimation was established. First, the predicted velocity arrays were evaluated at the measurement plane by interpolating the velocity data at the intersecting cell edges. The gamma function proposed by Graftieaux et al. [35] was used for vortex center identification on a plane with normal unity vector $\hat{z}$ :

$$
\begin{aligned}
\Gamma(P) & =\frac{1}{S} \int_{M \in \Omega} \frac{\left(\overrightarrow{P M} \times \vec{v}_{M}\right) \cdot \hat{z}}{\|\overrightarrow{P M}\| \cdot\left\|\vec{v}_{M}\right\|} d S \\
& =\frac{1}{S} \int_{M \in \Omega} \sin \left(\theta_{M}\right) d S .
\end{aligned}
$$

In Eq. $2, P$ and $M$ are points in the planar domain $\Omega$, which has total area $S$; $\vec{v}_{M}$ is the velocity vector at point $M$, and $\|\cdot\|$ denotes Euclidean vector norm; $\theta_{M}$ represents the angle between the velocity vector at point $M$ and the position vector, $P \vec{M}$. This formulation yields results in the $[0,1]$ interval, and represents the sine of the average angle under which an arbitrary point sees all of the velocity arrays in the domain. If the gamma function is evaluated at the swirl center of a rigid vortex, all of the velocity arrays are seen under a 90-degree angle, and $\Gamma=1$. As the real vortex is non-rigid and noncircular, the vortex center was assumed to be the point in the domain where the gamma value is maximum. Furthermore, in order to remove surface area dependency of the formulation, the velocity vectors at the evaluation plane were further interpolated onto a equally-spaced, uniform grid using cubic spline interpolation [36]. A total of 200 interpolation points per linear dimension was used, providing an average center of swirl resolution accuracy of about $0.41 \mathrm{~mm}$, and a total of 31015 gamma evaluation positions on the 
horizontal section. The gamma function evaluation was approximated to its formulation for a uniform grid discretization, having a total number of points $n_{p t s}$, as:

$$
\Gamma(P)=\frac{1}{n_{p t s}} \sum_{i=1}^{n_{p t s}}\left(\sin \left(\theta_{i}\right)\right) .
$$

The predicted swirl center positions were compared with the PIV measurements of Petersen and Miles [16]. In Figure 14 the predicted swirl center precession on a horizontal plane $3 \mathrm{~mm}$ below the firedeck is shown for three throttle configurations and at the three crank angles during the compression stroke already used for the tangential velocity profile study. Radii of uncertainty in the experimental measurements that were of the order of few millimeters, have not been included in the figure. Interestingly, all the simulations capture the counter-clockwise precession of the swirl center well at all three swirl ratios. Furthermore, the swirl center position, being stably placed on the exhaust-side semi-half of the combustion chamber, is consistently predicted by all the simulations. Only the case with $R_{s}=4.5$ shows some deviations in terms of the absolute swirl center positions compared to the experimental measurements, while both lower swirl ratio cases capture the swirl center positions very well. It should be noted that the eccentricity of the swirl center is only of the order of few millimeters, as the measurement plane was very close to the cylinder head.

As shown also in Figure 8, the in-cylinder vortical structure is significantly twisted. This can be seen also in terms of the swirl center position when the horizontal measurement plane was placed at different distances from the fire-deck. In Figure 15, the swirl center extrapolation from the PIV measure- 
ments at three planes respectively placed 3, 10, $18 \mathrm{~mm}$ below the fire-deck is again compared with the predictions. All of the cases show a consistent movement of the swirl center from the exhaust half of the combustion chamber towards the intake half when moving downwards towards the piston, and this behavior is quite similar at the different intake swirl ratios. The model was found to replicate this behavior well. However, the amount of eccentricity towards the intake side at the lowest plane positions was consistently under-predicted by about 10-15 mm. It should be noted that these inaccuracies reflect the fact that the comparison plane is very close to the fire-deck, where the impact of the presence of valves and valve seats on the local fluid flow is relevant.

The simulations show that the complex shape of the swirl flow affects significantly the overall momentum within the combustion chamber. Compared with the sector mesh simulation, where the rigid vortical structure is conserved throughout the compression stroke, as shown in Figure 16, a different behavior is seen. First, when the vortex captures the real, twisted and moving non-axisymmetric placement of the swirl centers, not all of the swirl centers throughout the combustion chamber height are aligned with the global center of mass at every horizontal section. Thus, part of the swirling velocity arrays count as negative components in the overall swirl ratio calculation. Furthermore, the full geometry representation incorporates details of the piston surface and of the cylinder head that act as barriers to the flow when, approaching TDC, the piston surface is extremely close to the cylinder head. This effect is not present in the sector mesh simulation, where no valve cut- 


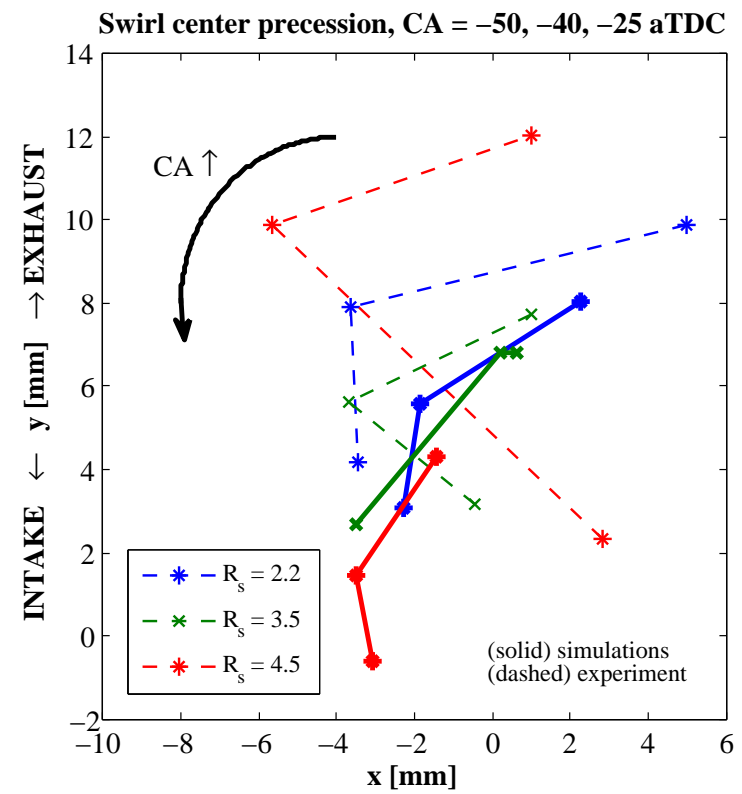

Figure 14: Swirl center precession during the compression stroke at a horizontal plane placed $3 \mathrm{~mm}$ below the firedeck. (solid) predictions, (lines) experiment. 


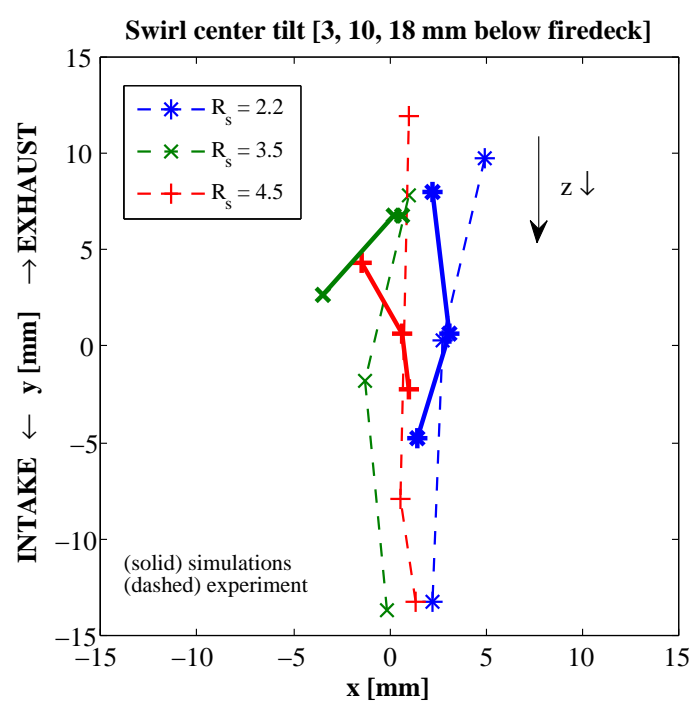

Figure 15: Vertical swirl center tilt 35 degrees before top dead centre. (solid) predictions, (lines) experiment.

outs or recesses are modeled. Thus, the swirl ratio predicted with the sector mesh shows a stronger increase during the compression stroke, as it is closer to idealized angular momentum conservation conditions.

A very different behavior is instead predicted by the full calculation which exhibits a much stronger momentum dissipation effect until after top dead center. Conversely, the decay appears to be slower late during the expansion stroke. This has a direct effect on the predicted in-cylinder turbulence, that significantly affects fuel-air mixing and combustion development, as shown in Figure 17. In particular, the turbulence model length scale is related to combustion chamber geometric details [37], and is similarly captured by both simulation approaches. However, the predicted turbulent kinetic energy and its dissipation rate differ by a factor of three, with the sector mesh approach dramatically underestimating the turbulence properties even after their arbi- 


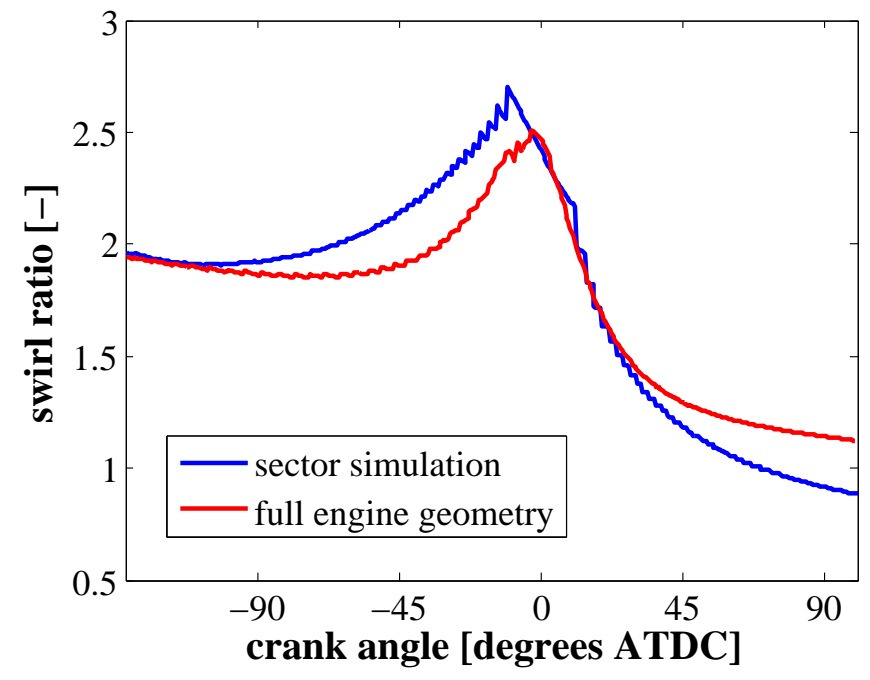

Figure 16: Comparison between predicted in-cylinder swirl ratios throughout the compression and expansion strokes with a sector mesh or full engine modelling for nominal $R_{s}=2.2$ configuration.

trarily high initialization at IVC. The high values of turbulent intensity and kinetic energy imposed at the initialisation are seen to be quickly dissipated in the axysimmetric flow simulation. It should be noted that, consistent with the underpredicted turbulence quantities, fuel-air mixing with sector mesh simulations of partially premixed combustion [5] is significantly underestimated.

\subsection{Impact of swirl generation throttling strategies on the in-cylinder flow structure}

With the fluid flow characteristics validated against the available experimental measurements, it was of interest to explore swirl effects on overall fluid flow structures. The impact of different swirl ratios on the ignition of a 

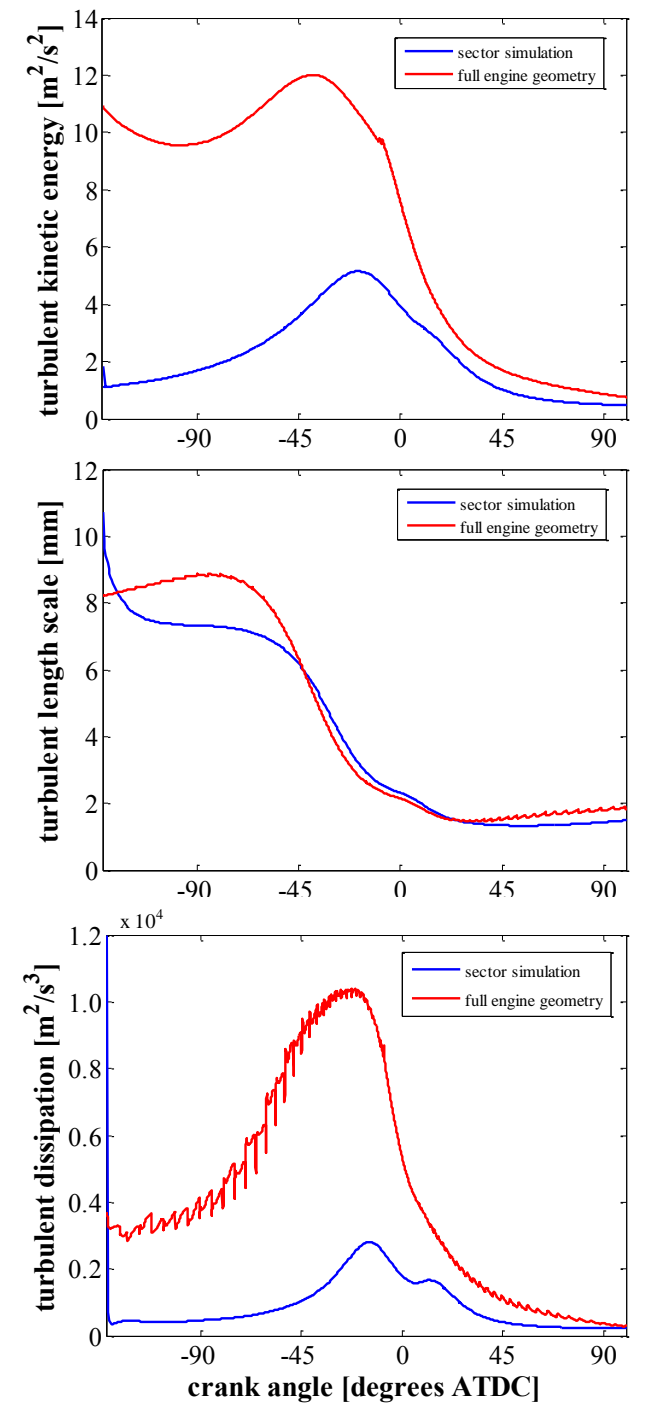

Figure 17: Comparison between predicted in-cylinder turbulent quentities throughout the compression and expansion strokes with a sector mesh or full engine modelling for nominal $R_{s}=2.2$ configuration. (top) average turbulent kinetic energy; (center) turbulent length scale; (bottom) turbulent dissipation $\epsilon$. 
partially-premixed fuel-air mixture following a single injection event occurring at $C A=-23.5^{\circ}$ ATDC has been studied experimentally [38]. In these experiments the four nominal swirl ratios of Table 2 were used, and it was found that ignition was advanced not only at increasing swirl ratio, but also at the lowest swirl ratio $R_{s}=1.5$. This was thought to result from rich mixture pockets being found in the squish region near top dead center [5]. Figure 18 shows the mass flux fraction of the cumulative intake mass entering the combustion chamber through the tangential port. According to the modeling results, in the fully open position the intake fluxes between the ports is extremely close to $50 \%$. However, the swirl enhancement or reduction strategies lead to imbalances: lower swirl ratios bring mass imbalance towards the helical port at an average of $0.47 \%$ per tangential throttle degree, while higher swirl ratios shift the mass imbalance towards the tangential port at a higher rate of an average of $0.61 \%$ per helical throttle degree.

The overall intake flow structure is significantly affected by the imbalances, as reported in Figure 19. At the reference operating condition, $R_{s}=2.20$, peak velocity magnitudes are seen within the helical port, and the local spin leads to a significantly tilted, and slightly chaotic, in-cylinder vortex structure. This behavior is significantly amplified as the swirl ratio is decreased up to $R_{s}=1.5$, where most of the mass flow previously entering through the tangential port is now missing. This leads to a much less coherent vortical structure at TDC that presents significantly more non-swirling velocities with stronger vertical components and a globally more chaotic structure.

On the contrary, as the flow through the tangential port becomes domi- 


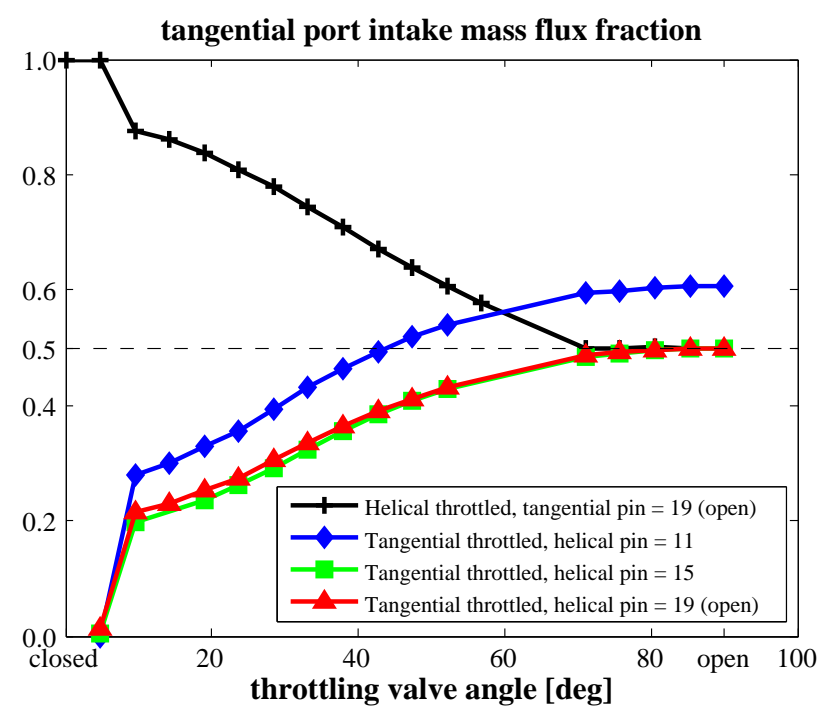

Figure 18: Cumulative intake mass flux fraction flowing through the tangential port versus throttled port valve orientation.

nant and high swirl ratios are achieved, the structure of the in-cylinder bulk flow progressively approximates a more regular, almost rigid vortex, with small vertical velocity components, and most streamlines almost homogeneously occupy the near-liner, bulk swirling region. Interestingly, in these cases the stronger near-liner momentum appears to confine the velocity components induced by the helical port within the center part of the cylinder, near the axis of symmetry.

\subsection{Flow field non-uniformity effects on temperature stratification}

Investigations on the effects of thermal and composition stratification on HCCI combustion [39, 40] have shown sensitivity of the start of combustion and of the combustion development to these parameters. In particular, a strong directionality of the ignition within the combustion chamber was 

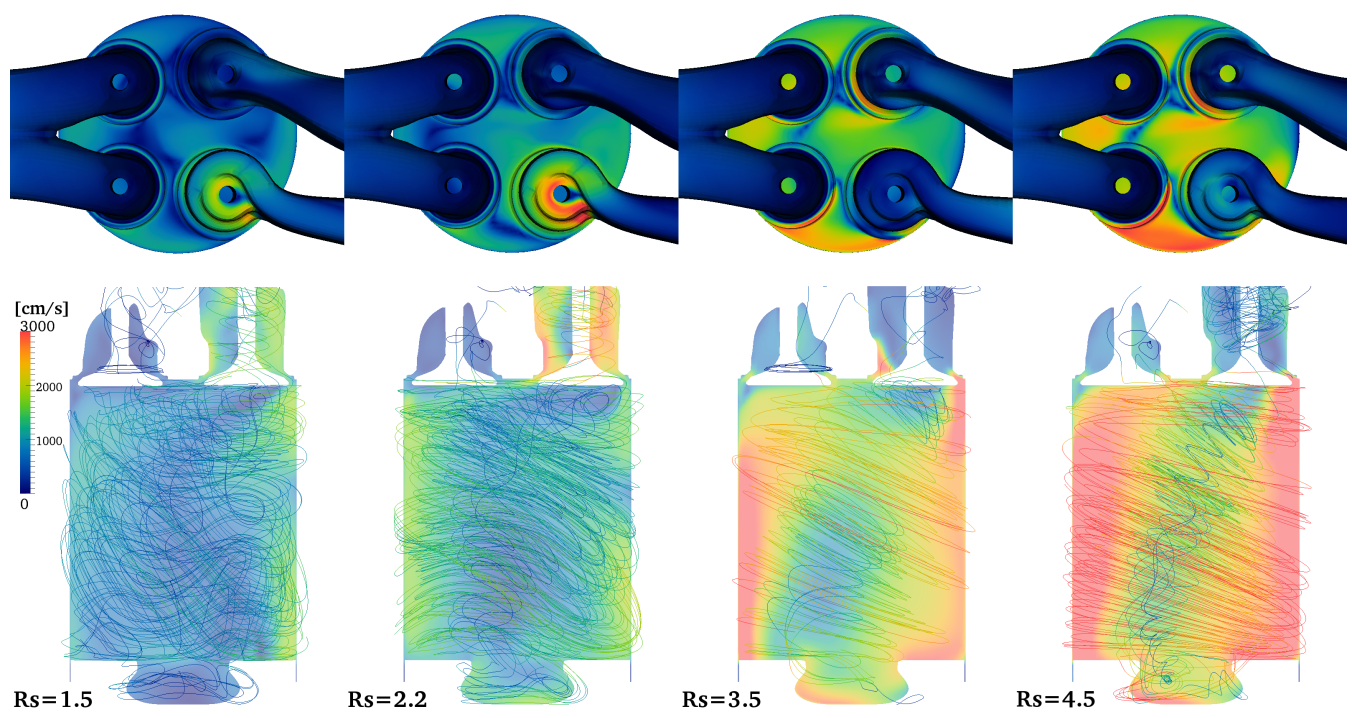

Figure 19: Predicted velocity magnitude contours at BDC during the intake stroke. Nominal swirl ratios: $R_{s}=1.5,2.2,3.5,4.5$. (top) port velocities, seen from the top; (bottom) vertical section crossing the intake valve axes, including in-cylinder velocity streamlines.

observed even in very well mixed fuel-air mixtures, where a purely thermal temperature stratification of about $20 \mathrm{~K}$ was present. The present full induction stroke simulations showed that similar temperature stratification is present in the engine in the current study, as reported in Figure 20 at intake valve closing, and in Figure 21 at top dead center, for the baseline $R_{s}=2.20$ operating condition. As previously seen in Figure 19, some of the swirl ratio generation strategies induce vortical structures that have fewer vertical components. As the temperature stratification at IVC conveys, the lack of vertical transport also leads to a less efficient scavenging of the warmer exhaust products that partially remain within the piston bowl. Thus, a significant temperature stratification of about $40 \mathrm{~K}$ is seen throughout the combustion chamber. More importantly, a temperature stratification of the order of $10 \mathrm{~K}$ 


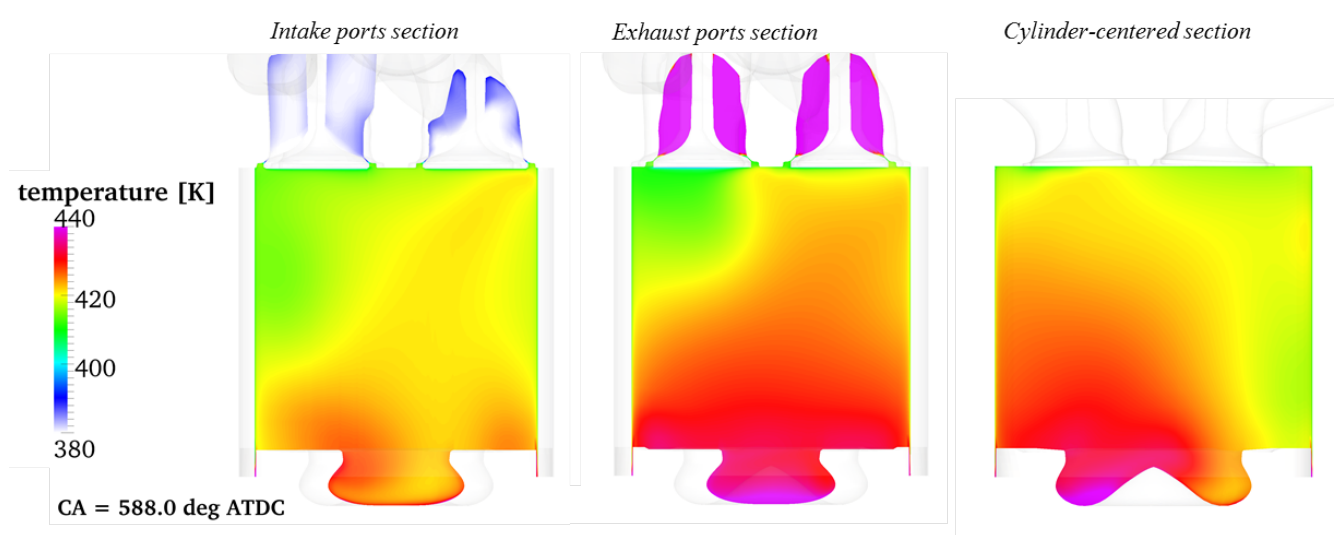

Figure 20: Predicted in-cylinder temperature stratification within the combustion chamber at IVC, $R_{s}=2.20$.

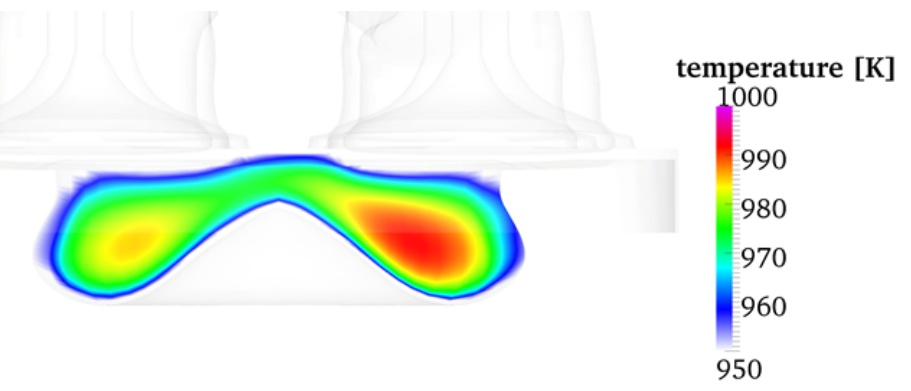

Figure 21: Predicted in-cylinder temperature stratification within the combustion chamber at TDC, $R_{s}=2.20$.

survives mixing occurring during compression until top dead center, where a warmer charge core is seen to be present within the piston bowl, located between the helical intake port and one of the exhaust ports. Analyzing the effects of temperature stratification on combustion was beyond the scope of the present study, but such levels of inhomogeneity are known to affect the overall engine combustion behavior in HCCI operation [40]. 


\section{Concluding Remarks}

The present study focused on the development and validation of fluid flow predictions of an optically accessible, single cylinder light-duty diesel engine. A computational model of the full engine geometry was developed, including the detailed geometry of the exhaust and intake ducts, up to the intake plenum. The use of a body-fitted mesh allowed resolution of wall boundary regions, including the cylinder liner, the valve seats, and the valve passages. A simplified but geometrically correct model of the port throttle valves was used to achieve different in-cylinder swirl ratios as seen in experiments. The derived swirl ratio predictions were compared for different swirl generation strategies, and the local flow field properties were validated against steadystate swirl bench and PIV measurements $[15,16]$. The validated results were then used to understand how different swirl generation strategies affect the in-cylinder flow structures, and the implications that simplified fluid flow modelling has on the predictiveness of widely adopted sector mesh simulations.

The following conclusions were drawn:

- The present RANS turbulence modeling approach is suitable for computational modelling of cycle-averaged experimental measurements. No noticeable differences in the flow field characteristics were seen when multi-cycle simulations were run;

- The simulation results for the reference, non-throttled operating condition with $R_{s}=2.2$ showed an excellent agreement with the measured 
flow quantities, including the overall swirl ratio, the tangential velocity profiles, and the swirl center tilt and precession;

- The simplified intake throttle model was able to replicate the experimental measurements;

- The simulations provide understanding of how the intake flows generate the in-cylinder swirl and reveal the flow structures seen when either the tangential or the helical ports are throttled. These results are helpful for spray and combustion simulations to understand the role of flow field non-uniformities on ignition in partially premixed combustion modes;

- The study revealed shortcomings of simplified sector mesh modelling on global fluid flow predictions and in-cylinder turbulence development, and their effects on local mixture temperature and composition stratification predictions;

- The present model can be used to further study turbulence, spray and combustion models for dilute, low-temperature combustion strategies.

\section{Acknowledgements}

This work was supported by the US Department of Energy Office of Vehicle Technologies under a contract administered by Sandia National Laboratories. Sandia is a multi-program laboratory operated by Sandia Corporation, a Lockheed Martin Company, for the United States Department of Energy's National Nuclear Security Administration under contract DEAC04-94AL85000. The authors also gratefully acknowledge ANSYS inc. for granting research licenses for the ICEM-CFD meshing product. 


\section{References}

[1] R. D. Reitz, Directions in internal combustion engine research, Combustion and Flame 160 (1) (2013) 1 - 8 . doi:http://dx.doi.org/10.1016/j.combustflame.2012.11.002.

URL http://www.sciencedirect.com/science/article/pii/S001021801200315X

[2] M. P. Musculus, P. C. Miles, L. M. Pickett, Conceptual models for partially premixed low-temperature diesel combustion, Progress in Energy and Combustion Science 39 (23) (2013) 246 - 283. doi:http://dx.doi.org/10.1016/j.pecs.2012.09.001.

URL http://www.sciencedirect.com/science/article/pii/S0360128512000548

[3] I. W. Ekoto, W. F. Colban, P. C. Miles, S. W. Park, D. E. Foster, R. D. Reitz, U. Aronsson, ivind Andersson, UHC and CO Emissions Sources from a Light-Duty Diesel Engine Undergoing Dilution-Controlled Low-Temperature Combustion, SAE Int. J. Engines 2 (2009) 411-430. doi:10.4271/2009-24-0043.

URL http://dx.doi.org/10.4271/2009-24-0043

[4] B. Petersen, P. Miles, D. Sahoo, Equivalence Ratio Distributions in a Light-Duty Diesel Engine Operating under Partially Premixed Conditions, SAE Int. J. Engines 5 (2012) 526-537. doi:10.4271/2012-01-0692.

URL http://dx.doi.org/10.4271/2012-01-0692

[5] F. Perini, A. Dempsey, R. Reitz, D. Sahoo, B. Petersen, P. Miles, A Computational Investigation of the Effects of Swirl Ratio and Injection Pressure on Mixture Preparation and Wall Heat Transfer in a Light-Duty Diesel Engine, SAE technical paper 2013-01-1105doi:10.4271/2013-01-1105.

URL http://dx.doi.org/10.4271/2013-01-1105

[6] R. Opat, Y. Ra, A. Manuel, D. Gonzalez, R. Krieger, R. D. Reitz, D. E. Foster, R. P. Durrett, R. M. Siewert, Investigation of Mixing and Temperature Effects on HC/CO Emissions for Highly Dilute Low Temperature Combustion in a Light Duty Diesel Enginedoi:10.4271/2007-01-0193.

URL http://dx.doi.org/10.4271/2007-01-0193 
[7] W. F. Colban, D. Kim, P. C. Miles, S. Oh, R. Opat, R. Krieger, D. Foster, R. P. Durrett, A. Manuel, D. Gonzalez, A Detailed Comparison of Emissions and Combustion Performance Between Optical and Metal Single-Cylinder Diesel Engines at Low Temperature Combustion Conditions, SAE Int. J. Fuels Lubr. 1 (2008) 505-519. doi:10.4271/2008-01-1066.

URL http://dx.doi.org/10.4271/2008-01-1066

[8] C. P. Koci, Y. Ra, R. Krieger, M. Andrie, D. E. Foster, R. M. Siewert, R. P. Durrett, I. Ekoto, P. C. Miles, Detailed Unburned Hydrocarbon Investigations in a HighlyDilute Diesel Low Temperature Combustion Regime, SAE Int. J. Engines 2 (2009) 858-879. doi:10.4271/2009-01-0928.

URL http://dx.doi.org/10.4271/2009-01-0928

[9] D. Kim, I. Ekoto, W. F. Colban, P. C. Miles, In-cylinder CO and UHC Imaging in a Light-Duty Diesel Engine during PPCI Low-Temperature Combustion, SAE Int. J. Fuels Lubr. 1 (2008) 933-956. doi:10.4271/2008-01-1602.

URL http://dx.doi.org/10.4271/2008-01-1602

[10] I. W. Ekoto, W. F. Colban, P. C. Miles, S. Park, D. E. Foster, R. D. Reitz, Sources of UHC Emissions from a Light-Duty Diesel Engine Operating in a Partially Premixed Combustion Regime, SAE Int. J. Engines 2 (2009) 1265-1289. doi:10.4271/2009-011446.

URL http://dx.doi.org/10.4271/2009-01-1446

[11] U. Aronsson, ivind Andersson, R. Egnell, P. C. Miles, I. W. Ekoto, Influence of Spray-Target and Squish Height on Sources of CO and UHC in a HSDI Diesel Engine During PPCI Low-Temperature Combustion, SAE technical paper 2009-012810doi:10.4271/2009-01-2810.

URL http://dx.doi.org/10.4271/2009-01-2810

[12] B. R. Petersen, I. W. Ekoto, P. C. Miles, An Investigation into the Effects of Fuel Properties and Engine Load on UHC and CO Emissions from a Light-Duty Optical Diesel Engine Operating in a Partially Premixed Combustion Regime, SAE Int. J. 
Engines 3 (2010) 38-55. doi:10.4271/2010-01-1470.

URL http://dx.doi.org/10.4271/2010-01-1470

[13] P. Miles, B. Petersen, D. Sahoo, The Impact of Injection Timing on Mixture Preparation and Chemical Kinetics in L-w-Temperature Diesel Combustion, in: 8th International Conference on Modeling and Diagnostics for Advanced Engine Systems COMODIA 2012, 2012.

[14] B. Petersen, D. Sahoo, P. C. Miles, Review of Equivalence Ratio Measurements in a Light-Duty Diesel Engine Operating in a Light-Load Partially Premixed Regime, in: THIESEL 2012 Conference on Thermo- and Fluid Dynamic Processes in Direct Injeciton Engines, 2012.

[15] R. M. Opat, Investigation of mixing and temperature effects on $\mathrm{UCH} / \mathrm{CO}$ emissions for highly dilute low temperature combustion in a light-duty Diesel engine, Ph.D. thesis, University of Wisconsin Madison (2006).

[16] B. Petersen, P. Miles, PIV Measurements in the Swirl-Plane of a Motored Light-Duty Diesel Engine, SAE Int. J. Engines 4 (2011) 1623-1641. doi:10.4271/2011-01-1285.

URL http://dx.doi.org/10.4271/2011-01-1285

[17] A. B. Dempsey, B.-L. Wang, R. D. Reitz, B. Petersen, D. Sahoo, P. C. Miles, Comparison of Quantitative In-Cylinder Equivalence Ratio Measurements with CFD Predictions for a Light Duty Low Temperature Combustion Diesel Engine, SAE Int. J. Engines 5 (2012) 162-184. doi:10.4271/2012-01-0143.

URL http://dx.doi.org/10.4271/2012-01-0143

[18] J. B. Heywood, Fluid Motion Within the Cylinder of Internal Combustion EnginesThe 1986 Freeman Scholar Lecture, Journal of Fluids Engineering 109 (1) (1987) 3-35. doi:10.1115/1.3242612.

URL http://dx.doi.org/10.1115/1.3242612

[19] C. Arcoumanis, J. H. Whitelaw, Fluid Mechanics of Internal Combustion Enginesa Review, Proceedings of the Institution of Mechanical Engineers, 
Part C: Journal of Mechanical Engineering Science 201 (1) (1987) 57-74. arXiv:http://pic.sagepub.com/content/201/1/57.full.pdf+html.

[20] R. Reitz, C. Rutland, Development and testing of diesel engine CFD models , Progress in Energy and Combustion Science 21 (2) (1995) 173 - 196. doi:http://dx.doi.org/10.1016/0360-1285(95)00003-Z.

URL http://www.sciencedirect.com/science/article/pii/036012859500003Z

[21] P. Miles, D. Choi, M. Megerle, B. RempelEwert, R. D. Reitz, M.-C. D. Lai, V. Sick, The Influence of Swirl Ratio on Turbulent Flow Structure in a Motored HSDI Diesel Engine - A Combined Experimental and Numerical Studydoi:10.4271/2004-01-1678. URL http://dx.doi.org/10.4271/2004-01-1678

[22] H.-W. Ge, R. D. Reitz, W. Willems, Modeling the Effects of In-Cylinder Flows on HSDI Diesel Engine Performance and Emissions, SAE Int. J. Fuels Lubr. 1 (2008) 293-311. doi:10.4271/2008-01-0649.

URL http://dx.doi.org/10.4271/2008-01-0649

[23] D. P. Towers, C. E. Towers, Cyclic variability measurements of in-cylinder engine flows using high-speed particle image velocimetry, Measurement Science and Technology 15 (9) (2004) 1917.

URL http://stacks.iop.org/0957-0233/15/i=9/a=032

[24] H. W. R. Dembinski, H.-E. Angstrom, Optical Study of Swirl during Combustion in a CI Engine with Different Injection Pressures and Swirl Ratios Compared with Calculationsdoi:10.4271/2012-01-0682.

URL http://dx.doi.org/10.4271/2012-01-0682

[25] A. A. Amsden, P. Orourke, T. Butler, KIVA-2: A computer program for chemically reactive flows with sprays, NASA STI/recon technical report N 89 (1989) 27975.

[26] A. A. Amsden, KIVA-3V: A block-structured KIVA program for engines with vertical or canted valves, Tech. rep., Los Alamos National Lab., NM (United States) (1997). 
[27] D. J. Torres, M. F. Trujillo, KIVA-4: An unstructured ALE code for compressible gas flow with sprays, Journal of Computational Physics 219 (2) (2006) 943 - 975. doi:http://dx.doi.org/10.1016/j.jcp.2006.07.006.

URL http://www.sciencedirect.com/science/article/pii/S002199910600338X

[28] Z. Han, R. D. Reitz, Turbulence Modeling of Internal Combustion Engines Using RNG k-epsilon Models, Combustion Science and Technology 106 (4-6) (1995) 267-295. arXiv:http://www.tandfonline.com/doi/pdf/10.1080/00102209508907782, doi:10.1080/00102209508907782.

URL http://www.tandfonline.com/doi/abs/10.1080/00102209508907782

[29] F. Perini, E. Galligani, R. D. Reitz, An Analytical Jacobian Approach to Sparse Reaction Kinetics for Computationally Efficient Combustion Modeling with Large Reaction Mechanisms, Energy \& Fuels 26 (8) (2012) 4804-4822. arXiv:http://pubs.acs.org/doi/pdf/10.1021/ef300747n, doi:10.1021/ef300747n.

URL http://pubs .acs.org/doi/abs/10.1021/ef300747n

[30] F. Perini, E. Galligani, R. D. Reitz, A study of direct and Krylov iterative sparse solver techniques to approach linear scaling of the integration of chemical kinetics with detailed combustion mechanisms, Combustion and Flame 161 (5) (2014) 1180 - 1195. doi:http://dx.doi.org/10.1016/j.combustflame.2013.11.017.

URL http://www.sciencedirect.com/science/article/pii/S0010218013004306

[31] F. Perini, High-dimensional, unsupervised cell clustering for computationally efficient engine simulations with detailed combustion chemistry , Fuel 106 (0) (2013) 344 356. doi:http://dx.doi.org/10.1016/j.fuel.2012.11.015.

URL http://www.sciencedirect.com/science/article/pii/S0016236112008915

[32] F. Perini, B. D. Adhikary, J. H. Lim, X. Su, Y. Ra, H. Wang, R. Reitz, Improved Chemical Kinetics Numerics for the Efficient Simulation of Advanced Combustion Strategies, SAE International Journal of Engines 7 (1) (2014) 243-255. arXiv:http://saeeng.saejournals.org/content/7/1/243.full.pdf+html, 
doi:10.4271/2014-01-1113.

URL http://saeeng. saejournals.org/content/7/1/243. abstract

[33] M. Bergin, R. Reitz, Effect of Flowfield Non-Uniformities on Emissions Predictions in HSDI Engines, SAE technical paper 2011-01-0821doi:10.4271/2011-01-0821.

URL http://dx.doi.org/10.4271/2011-01-0821

[34] D. M. Heim, J. B. Ghandhi, Investigation of swirl meter performance, Proceedings of the Institution of Mechanical Engineers, Part D: Journal of Automobile Engineering $225 \quad$ (8) (2011) 10671077. arXiv:http://pid.sagepub.com/content/225/8/1067.full.pdf+html, doi:10.1177/0954407011404763.

URL http://pid.sagepub.com/content/225/8/1067. abstract

[35] L. Graftieaux, M. Michard, N. Grosjean, Combining PIV, POD and vortex identification algorithms for the study of unsteady turbulent swirling flows, Measurement Science and Technology 12 (9) (2001) 1422.

URL http://stacks.iop.org/0957-0233/12/i=9/a=307

[36] C. de Boor, A Practical Guide to Splines, no. v. 27 in Applied Mathematical Sciences, Springer, 2001.

URL http://books.google.com/books?id=mOQDJvBI_ecC

[37] Z. Han, R. Reitz, F. Corcione, G. Valentino, Interpretation of k-epsilon computed turbulence length-scale predictions for engine flows, Symposium (International) on Combustion 26 (2) (1996) 2717 - 2723. doi:http://dx.doi.org/10.1016/S00820784(96)80108-1.

URL http://www.sciencedirect.com/science/article/pii/S0082078496801081

[38] D. Sahoo, B. Petersen, P. Miles, The impact of swirl ratio and injection pressure on fuel-air mixing in a light-duty diesel engine, in: ASME 2012 Internal Combustion Engine Division Spring Technical Conference ICES2012, 2012. 
[39] J. E. Dec, W. Hwang, M. Sjberg, An Investigation of Thermal Stratification in HCCI Engines Using Chemiluminescence Imaging, SAE technical paper 2006-011518doi:10.4271/2006-01-1518.

URL http://dx.doi.org/10.4271/2006-01-1518

[40] R. E. Herold, J. M. Krasselt, D. E. Foster, J. B. Ghandhi, D. L. Reuss, P. M. Najt, Investigations into the Effects of Thermal and Compositional Stratification on HCCI Combustion Part II: Optical Engine Results, SAE Int. J. Engines 2 (2009) 10341053. doi:10.4271/2009-01-1106.

URL http://dx.doi.org/10.4271/2009-01-1106 